\title{
New adjustable suture technique for trabeculectomy
}

\section{Nova técnica de sutura ajustável para trabeculectomia}

Vespasiano Rebouças-Santos ${ }^{1}$, Daniel Meira-Freitas ${ }^{1}$ Angelino Júlio Cariello ${ }^{1}$, Tiago dos Santos Prata ${ }^{1}$, Sergio Henrique Teixeira ${ }^{1}$

\section{ABSTRACT}

Purpose:To describe an adjustable suture (AS) experimental model that allows for tightening, loosening and retightening of the suture tension in trabeculectomy. Methods: Standard trabeculectomy was performed in fifteen pig eyeballs. All pig eyes were tested twice: one test with conventional suture in both flap's corners (conventional suture group) and another test with a conventional suture at one corner and an adjustable suture in the other corner (AS group). The order in which each test was performed was defined by randomization. Intraocular pressure was measured at three time points: T1) when the knots were tightened; T2) when the AS was loosened or the conventional knot was removed; and T3) when the AS was retightened in the AS group or five minutes after the knot removal in the conventional suture group.

Results: The mean Intraocular pressure was similar between the two groups at time point 1 ( $p=0.97)$. However, significant Intraocular pressure differences were found between eyes in the conventional and adjustable suture groups at time points $2\left(12.6 \pm 4.2\right.$ vs $16.3 \pm 2.3 \mathrm{cmH}_{2} \mathrm{O}$, respectively, $\left.\mathrm{p}=0.006\right)$ and $3(12.2 \pm 4.0 \mathrm{vs}$ $26.4 \pm 1.7 \mathrm{cmH}_{2} \mathrm{O}$, respectively; $\mathrm{p}=0.001$ ). While the conventional technique allowed only Intraocular pressure reduction (following the knot removal; T2 and T3), the AS technique allowed both Intraocular pressure reduction (T2) and elevation (T3) through the management (loosening and retightening) of the suture.

Conclusion: This experimental model provides an effective noninvasive postoperative mechanism of suture tension adjustment.

Keywords: Glaucoma/surgery; Trabeculectomy; Suture techniques; Intraocular pressure; Animals; Swine

\section{RESUMO}

Objetivo: Descrever uma nova técnica de sutura ajustável para o "flap" da trabeculectomia (TREC), que permite apertar e folgar a sutura no pós-operatório.

Métodos: Foram realizadas trabeculectoomia em 15 olhos de porco. Todos os olhos de porco foram testados duas vezes; um teste com sutura convencional nas duas extremidades do "flap" (grupo sutura convencional), outro teste com sutura convencional em uma das extremidades e na outra extremidade a sutura ajustável proposta por esse trabalho (grupo sutura ajustável). A ordem de qual teste seria realizado primeiro em cada olho foi definida por sorteio. A pressão intraocular foi medida de forma direta em três momentos: T1) Todas as suturas apertadas; T2) Após lise de uma sutura convencional ou de afrouxar a sutura ajustável; T3) Após apertar novamente a sutura ajustável ou no caso do teste com as duas suturas convencionais após 5 minutos da lise de uma das suturas.

Resultados: No primeiro momento de medida dapressão intraocular (T1) as pressões médias foram similares entre os dois grupos ( $p=0.97$ ). No entanto, diferenças significativas em relação a pressão intraocular foram encontradas entre os grupos de sutura convencionale ajustável nos tempos $2\left(12,6 \pm 4,2 \mathrm{vs} 16,3 \pm 2,3 \mathrm{CmH}_{2} \mathrm{O}\right.$, respectivamente; $p=0,006)$ e $3(12,2 \pm 4,0$ vs $26,4 \pm 1.7 \mathrm{cmH} O$, respectivamente; $p=0,001)$. Enquanto a técnica convencional permitiu somente a redução da pressão intraocular após a remoção da sutura (T2 e T3), a técnica de sutura ajustável permitiu tanto a redução (T2) quanto a elevação da pressão intraocular (T3) através do manejo da sutura.

Conclusão: Esse modelo experimental demonstrou a eficácia de uma possível técnica não-invasiva para ajuste da tensão da sutura do "flap" no pós-operatório da trabeculectomia.

Descritores: Glaucoma/cirurgia; Trabeculectomia; Técnicas de sutura; Pressão intraocular; Animais; Suínos

\section{INTRODUCTION}

Trabeculectomy has been well established as a safe and effective surgical alternative for intraocular pressure (IOP) reduction ${ }^{(1,2)}$. Overfiltration is a common postoperative complication, which may lead to anterior chamber shallowness, choroidal detachment and hypotony maculopathy ${ }^{(3)}$. During the postoperative period, the physician can intervene to maintain proper functioning of the surgical fistulae and IOP reduction through the mechanical removal/loosening of the adjustable suture (AS) or through laser suture lysis ${ }^{(1,4-6)}$. The possibility of drainage reduction (IOP increase) through noninvasive suture adjustment is not yet available to avoid ocular hypotony in cases of trabeculectomy overfiltration.

The purpose of this study was to describe an exvivo experimental model of AS for the scleral flap of the trabeculectomy that allows for the tightening, loosening and retightening of suture tension during the postoperative period.

\section{METHODS}

This study was conducted at the Surgical Research and Training Center of the Department of Ophthalmology of the Federal University of São Paulo, and the protocol was previously approved by the institutional Ethics Committee.

\section{Porcine eyes}

Freshly excised pig eyes were obtained from a local slaughterhouse, washed thoroughly and transported in $0.9 \%$ saline solution at a temperature of $5^{\circ} \mathrm{C}$. All eyes were examined under a surgical micros-

Physician, Department of Ophthalmology, Universidade Federal de São Paulo - UNIFESP - São Paulo (SP) - Brazil.

Funding: No specific financial support was available for this study.

Disclosure of potential conflicts of interest: V.Rebouças-Santos, None; D.Meira-Freitas, None; A.J.Cariello, None; T.S.Prata, None; S.H.Teixeira, None.

Correspondence address: Vespasiano Rebouças-Santos. Rua Botucatu, 822 - São Paulo (SP) 04023-062 - Brazil - E-mail: santosvespasiano@hotmail.com

Institutional review board number (Comitê de Ética em Pesquisa da UNIFESP): 1322/10. 
cope, and those in unsatisfactory condition (e.g., corneal opacity or perforation) were not included in the study.

\section{Procedures}

Each eyeball was fixed on a suitable support. All surgeries were performed by the same surgeon according to the technique previously described by Lee et al., ${ }^{(7)}$. Initially, two clear cornea paracenteses were performed. Then, the surgeon made an incision through the conjunctiva and created a partial-thickness scleral flap with a crescent blade. Prior to perform the trabeculectomy, two 18-gauge infusion cannulae were installed in the paracentesis, one with the saline solution bottle at a $40 \mathrm{~cm}$ height and the other for the water column (Figure 1). A conventional 10.0 nylon suture was performed at the first corner of the scleral flap. The second suture was randomly chosen to be a conventional suture (CS) or AS by a true random number generator (random.org). All pig eyes were tested twice, one test with CS in both flap's corner (conventional suture group - CSG), another test with conventional suture at one corner and other corner the adjustable suture (adjustable suture group - ASG).

The water column technique was used to measure the IOP at three different time points: 1) when the knots were tightened; 2) when the AS was loosened in the ASG or the conventional knot was removed in the CSG; and 3) when the AS was retightened or five minutes after the second measurement in the conventional suture group. The AS was loosened and retightened from its corneal end without touching the sclera or scleral flap. At the end of the surgery, the CS or AS technique was randomly chosen and performed on the second corner of the scleral flap in a crossover fashion. Thus, both suture techniques were tested in the same eyeballs.

\section{Adjustable suture teChNiQue}

This new AS was based in a slip-knot technique as shown in the figure 2. The difference was to pass the two sutures ends into the cornea two times. The corneal suture ends can be use for tighten or loosening flap's knot without touch the flap or conjunctival flap, simulating a postoperative management. The technique: the suture is first passed through the corneal periphery, parallel to the limbus, and then passed perpendicularly from the cornea to the limbus. Then, it

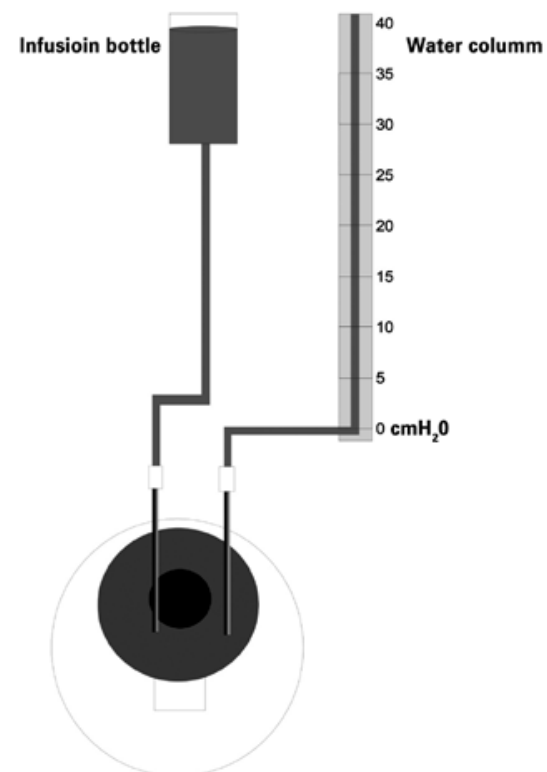

Figure 1. Representative picture of the water column system used for intraocular pressure measurement. is passed through the intact sclera toward the scleral flap. The string is pulled and the needle is positioned at the limbus. A single throw is performed, grasping the needle end of the suture. The needle end of the suture is pulled to tighten the slipknot. The suture is then passed through the intact sclera, perpendicularly to the limbus, and then through clear cornea, parallel to the limbus. The needle end of the suture is cut flush with the cornea.

\section{Statistical analysis}

The intra and intergroup IOP variations and mean values were compared using a mixed linear model. An open source statistical software ( $R$ - version 2.15.1) was used for all analyses. Statistical significance was set at $p<0.05$.

\section{RESULTS}

Fifteen porcine eyes were included in the study. In the CSG, the mean IOP at time point 1 was $26.8 \pm 0.8 \mathrm{cmH}_{2} \mathrm{O}$, decreasing to 12.6 $\pm 4.2 \mathrm{cmH}_{2} \mathrm{O}$ at time point $2(\mathrm{p}<0.01)$ and remaining stable at $12.2 \pm$ $4.0 \mathrm{CmH}_{2} \mathrm{O}$ at the third time point $(\mathrm{p}<0.01)$. In ASG, the mean IOP at time point 1 was $26.8 \pm 0.9 \mathrm{cmH}_{2} \mathrm{O}$, decreasing to $16.3 \pm 2.3 \mathrm{~cm} \mathrm{H}_{2} \mathrm{O}$ at time point $2(p<0.01)$, and returning to $26.4 \pm 1.7 \mathrm{cmH}_{2} \mathrm{O}$ at time point $3(p=0.31)$. Figure 3 shows the IOP variations at the three time points.

The mean baseline IOP was similar between the groups $(p=0.97)$. However, significant differences were found at time points 2 (12.6 \pm 4.2 and $16.3 \pm 2.3 \mathrm{cmH}_{2} \mathrm{O}$, respectively, $\left.\mathrm{p}=0.006\right)$ and 3 (12.2 \pm 4.0 and $26.4 \pm 1.7 \mathrm{cmH}_{2} \mathrm{O}$, respectively, $\left.\mathrm{p}=0.001\right)$.

\section{DISCUSSION}

In this ex vivo experimental model, we described a novel AS for the scleral flap used in trabeculectomy that allows for both increase and reduction of the aqueous humor outflow through the surgical fistulae during the postoperative period. Our results suggest that this new suture technique might improve IOP control in patients with glaucoma who undergo trabeculectomy.

Overfiltration in the early postoperative period of the trabeculectomy is a common complication that can lead to ocular hypotony ${ }^{(2)}$. To reduce the incidence of complications associated with overfiltration, many surgeons advocate the use of a tight suture on the scleral flap followed by laser suture lysis or suture loosening/removal in cases in which releasable suture techniques were used ${ }^{(2)}$. However, these methods carry an intrinsic risk for the development of hyperfiltration after loosening or removal of the suture ${ }^{(5)}$. Currently, the available treatment for a hyperfiltrating trabeculectomy includes an occlusive eyepad, a bandage contact lens, reduction of the use of steroid eye drops, subconjunctival injection of autologous blood, contention suture, transconjunctival suture of the scleral flap and surgical revision with resuture of the scleral flap after conjunctival opening ${ }^{(8-10)}$.

The possibility of tightening, loosening and retightening of the suture introduced in this study is a potential effective, reversible and non-invasive approach to minimize trabeculectomy hyperfiltration. The suture adjustment was easily performed through the manipulation of the corneal ends of the suture, without accessing the scleral flap. We presume that this method could be applied in patients under slit-lamp examination, avoiding a new surgical procedure.

Anatomical differences between human and porcine eyes, the absence of blood circulation and infusion flow rates that were higher than physiologic aqueous flow rates were the main limitations of this experimental model. In this study, the same experimental model was used to perform and compare the two suture techniques, which probably mitigated the influence of the chosen method in our results.

\section{CONCLUSION}

This experimental study demonstrated this novel suture technique as an effective and non-invasive alternative for tightening, 

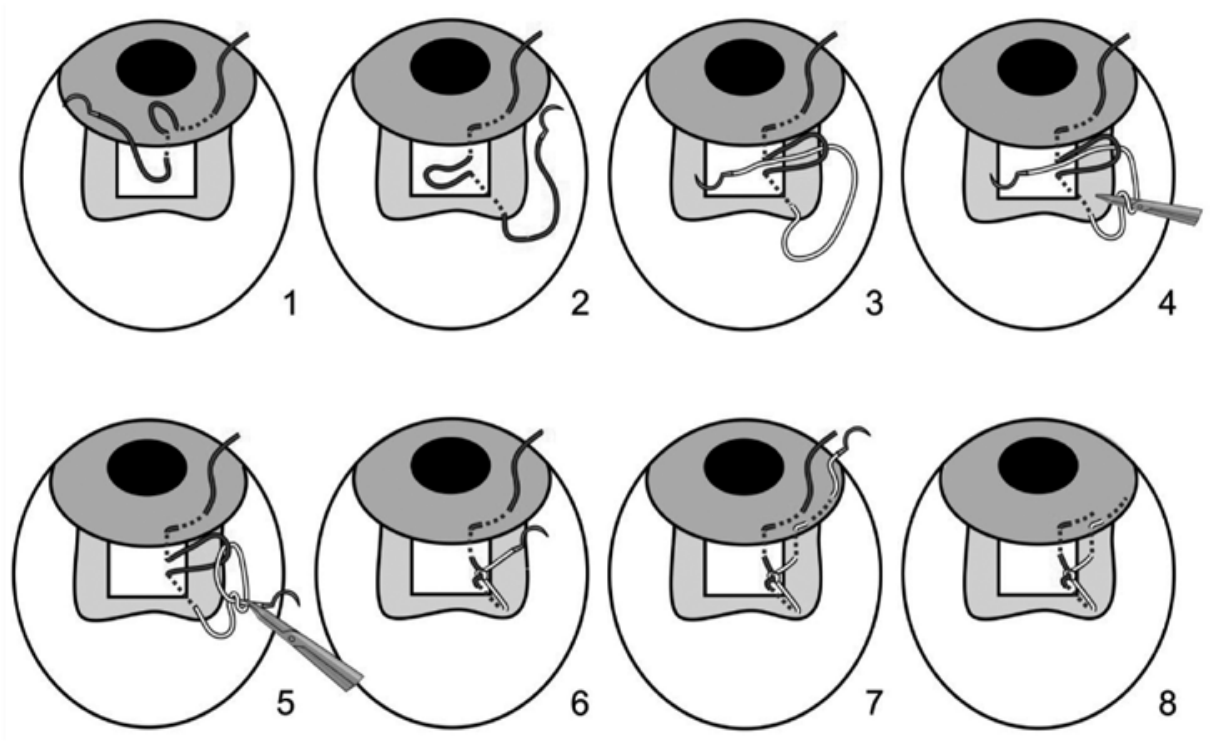

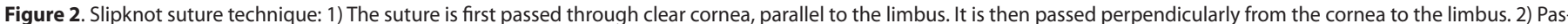

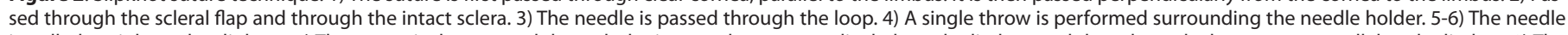

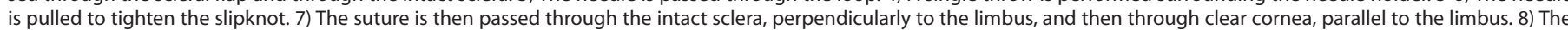
needle end of the suture is cut close to the cornea.
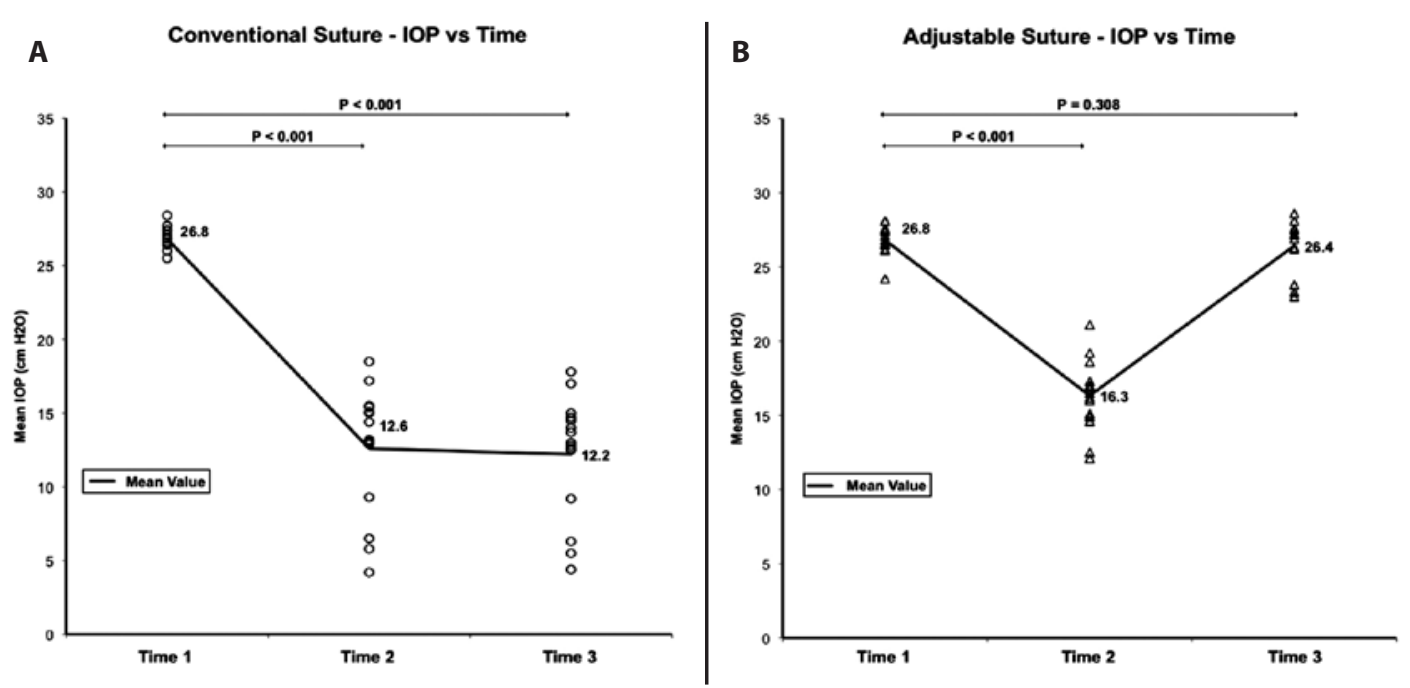

Figure 3. Mean intraocular pressure variation at each time point. A) Conventional suture technique. B) Adjustable suture technique.

loosening and retightening the scleral flap during the postoperative period in porcine eyes. Further in vivo experimental and clinical studies could elucidate the potential advantages and safety of this new suture technique.

\section{REFERENCES}

1. Caporossi A, Balestrazzi A, Malandrini A, Tosi GM, Caporossi T, Frezzotti P, et al. A randomized prospective study comparing trabeculectomy with and without the use of a new removable suture. Int Ophthalmol. 2009;29(5):359-65.

2. Simsek T, Citirik M, Batman A, Mutevelli S, Zilelioglu O. Efficacy and complications of releasable suture trabeculectomy and standard trabeculectomy. Int Ophthalmol. 2005;26(1-2):9-14.

3. de Barros DS, Gheith ME, Siam GA, Katz LJ. Releasable suture technique. J Glaucoma. 2008;17(5):414-21.

4. Kayikcioglu OR, Emre S, Kaya Z. Trabeculectomy combined with deep sclerectomy and scleral flap suture tension adjustment under an anterior chamber maintainer: new modification of trabeculectomy. Int Ophthalmol. 2010;30(3):271-7.

5. Kobayashi H, Kobayashi K. A comparison of the intraocular pressure lowering effect of adjustable suture versus laser suture lysis for trabeculectomy. J Glaucoma. 2011; 20(4):228-33.

6. Birchall W, Wells AP. The effect of scleral flap edge apposition on intraocular pressure control in experimental trabeculectomy. Clin Experiment Ophthalmol. 2008;36(4):353-7.

7. Lee GA, Chiang MY, Shah P. Pig eye trabeculectomy-a wet-lab teaching model. Eye (Lond). 2006:20(1):32-7.

8. Letartre L, Basheikh A, Anctil JL, Des Marchais B, Goyette A, Kasner OP, et al. Transconjunctival suturing of the scleral flap for overfiltration with hypotony maculopathy after trabeculectomy. Can J Ophthalmol. 2009:44(5):567-70.

9. Maruyama K, Shirato S. Efficacy and safety of transconjunctival scleral flap resuturing for hypotony after glaucoma filtering surgery. Graefes Arch Clin Exp Ophthalmol. 2008:246(12):1751-6.

10. Eha J, Hoffmann EM, Wahl J, Pfeiffer N. Flap suture--a simple technique for the revision of hypotony maculopathy following trabeculectomy with mitomycin C. Graefes Arch Clin Exp Ophthalmol. 2008;246(6):869-74. 